\title{
Studies on the Intestinal Surface Acid Microclimate: Developmental Aspects
}

\author{
HAMID M. SAID, RITA SMITH, AND REYADH REDHA \\ Departments of Pediatric Gastroenterology, Molecular Physiology and Biophysics, Vanderbilt University School \\ of Medicine, Nashville, Tennessee 37232
}

\begin{abstract}
The existence and general characteristics of the intestinal surface acid microclimate (ISAM) in the developing intestine of suckling and weanling rats were examined. ISAM pH measurements were performed in vitro using a sensitive glass $\mathrm{pH}$-microelectrode. The results showed that the ISAM does exist in both suckling and weanling rat intestine. In both suckling and weanling rats, ISAM pH was significantly $(p<0.01)$ lower in the jejunum than in the ileum, an observation similar to that previously reported in the small intestine of adult rats. In the colon, however, ISAM pH of suckling rats was significantly ( $p$ $<0.01$ ) lower than that of weanling and adult rats. Studies on the relationship between jejunal ISAM pH of weanling rats and incubation buffer $\mathrm{pH}$ showed that the two are not in equilibrium. Jejunal ISAM pH of weanling rats was significantly inhibited by: 1$)$ the mucolytic agent $\mathrm{N}$-acetylL-cysteine, 2) stirring of the incubation medium, 3) $\mathrm{Na}^{+}$ removal, 4) glucose removal (or substitution by the unmetabolizable galactose), and 5) metabolic inhibitors (iodoacetate and dinitrophenol). These results demonstrate the existence of the ISAM in the developing intestine of suckling and weanling rats and shows the dependence of the ISAM on $\mathrm{Na}^{+}$, metabolizable substrate(s) and normal intracellular metabolism. Furthermore, surface mucus appears to play a role in maintaining the ISAM, most probably through retaining the $\mathrm{H}^{+}$at the intestinal surface. (Pediatr Res 22: 497-499, 1987)
\end{abstract}

\section{Abbreviations}

ISAM, intestinal surface acid microclimate

NAC, $\mathrm{N}$-acetyl cysteine

IA, iodoacetate

DNP, dinitrophenol

The existence of a layer of hydrogen ions at the surface of the intestine, the so-called ISAM, has been invoked by Hogben et al. (1) to explain discrepancies between experimental and theoretical rates of transport of weak electrolytes. Subsequent studies by us and others have demonstrated, by means of direct measurements using sensitive $\mathrm{pH}$-microelectrodes, the existence of the ISAM in adult rats and human intestine (2-5). Furthermore, our studies in adult rats have shown that the ISAM requires normal intracellular metabolism, glucose, and $\mathrm{Na}^{+}$in the incubation medium for its existence (4). Recent findings have indicated that the ISAM plays a critical role in the absorption process of certain

Received February 23, 1987; accepted May 29, 1987

Supported by NIH Grants DK 39501-01 and NIDDKD AM 26657.

Correspondence and reprint requests Dr. H. M. Said, D-4113 MCN, Vanderbilt University School of Medicine, Nashville, TN 37232. nutrients such as folate $(6-8)$, peptides $(9,10)$, and fatty acids (11).

The structure and functions of the gastrointestinal tract undergo ontogeny during early stages of life (see Refs. 12 and 13 for review). This includes: 1) changes in ion and other substrate fluxes across the intestinal brush border membrane, 2) changes in brush border membrane fluidity and composition, 3) changes in intestinal brush border membrane enzymes, and 4) changes in villous and crypt height $(12,13)$. No study is available describing changes in the intestinal surface microenvironment during development, i.e. the suckling and weanling periods. Such studies are important since, as mentioned above, that the ISAM plays an important role in the absorption of certain nutrients that are required for maintaining the rapid growth and development of the young animal. In this study we examined the existence of the ISAM in suckling and weanling rats and determined its general characteristics.

\section{MATERIALS AND METHODS}

Two days after birth Sprague-Dawley rat pups (Harlan, Indianapolis, IN) were distributed among mothers to maintain a litter size of nine to 10 pups until the time of the study. Mothers and weanling rats were fed Purina Rat Chow and tap water ad libitum. The National Council's guidelines for the care and use of laboratory animals were followed.

All $\mathrm{pH}$ measurements were performed with a sensitive glass $\mathrm{pH}$ microelectrode (MI-404 membrane $\mathrm{pH}$ microelectrode; $\mathrm{Mi}$ croelectrodes Inc., Londonderry, $\mathrm{NH}$ ) as previously described (4). This $\mathrm{pH}$ microelectrode has a flat, $\mathrm{pH}$-sensitive tip that was chosen to avoid damage to the intestinal mucosa during experimentation. The $\mathrm{pH}$ microelectrode has a response time of less than $15 \mathrm{~s}$, a pH range of 0 to 14 , an almost ideal Nernstein slope, and excellent selectivity (no significant interference by other cations). The reference electrode was the MI-402 microreference electrode (Microelectrodes, Inc.) which was dipped into the same incubation medium as the $\mathrm{pH}$ microelectrode. Both electrodes were connected to a Beckman digital pH meter (Beckman Zeromatic pH I 43; Beckman Instruments, Inc., Fullerton, CA). A micromanipulator (Brinkman Instruments Co., Orange, $C A$ ) was used to hold and control the movement of the $\mathrm{pH}$ microelectrode during experimentation. Krebs-Ringer phosphate buffer was used as the incubation medium and contained (unless otherwise stated): $20 \mathrm{mM} \mathrm{NaH}{ }_{2} \mathrm{PO}_{4}, 125 \mathrm{mM} \mathrm{NaCl}, 4.93 \mathrm{mM} \mathrm{KCl}, 1.23$ $\mathrm{mM} \mathrm{MgSO}_{4}, 0.85 \mathrm{mM} \mathrm{CaCl}_{2}$, and $10 \mathrm{mM}$ glucose. The incubation medium was continuously oxygenated with $100 \%$ oxygen and was kept at $37^{\circ} \mathrm{C}$ at all times during experimentation. Buffer $\mathrm{pH}$ was adjusted using $1 \mathrm{M} \mathrm{HCl}$ or $1 \mathrm{M} \mathrm{NaOH}$.

In vitro ISAM pH measurements. Suckling (14- to 15-day-old) and weanling (23- to 25-day-old) rats were killed by an overdose of ether; the abdomen was opened through a midline incision, and the part of intestine under investigation was removed, 
washed with ice-cold buffer, and a flat $1-\mathrm{cm}^{2}$ strip of intestinal tissue was prepared from the middle portion of the section. The flat strip of tissue was then held by dissecting pins on a cork base of a glass vessel with the mucosal surface facing the incubation medium. Eight milliliters of Krebs-Ringer phosphate buffer was then added and incubation was performed at $37^{\circ} \mathrm{C}$. The preparation period of the tissue did not exceed $1.5 \mathrm{~min}$, therefore minimizing possible deterioration of tissue viability. The $\mathrm{pH}$ measurements were begun by recording the incubation buffer $\mathrm{pH}$. Then the ISAM $\mathrm{pH}$ was measured by carefully racking down the $\mathrm{pH}$ microelectrode, using the micromanipulator, onto the surface of tissue until the surface could be seen to slightly distort. Stable ISAM $\mathrm{pH}$ reading was achieved within 2 to 3 min after racking down the $\mathrm{pH}$ microelectrode onto the surface of the tissue.

In the suckling rat, the $20 \mathrm{~cm}$ of the small intestine that followed the first $7 \mathrm{~cm}$ was considered as the jejunum and the last $20 \mathrm{~cm}$ of the small intestine was considered as the ileum. In the weanling rat, the $25 \mathrm{~cm}$ of the small intestine that followed the first $10 \mathrm{~cm}$ was considered as the jejunum and the last $25 \mathrm{~cm}$ of the small intestine was considered as the ileum. The viability of the intestinal tissue preparation used for the in vitro ISAM pH measurements was assessed previously $(4,14)$ by determining the ability of the tissue to accumulate the unmetabolizable amino acid $\alpha$-amino isobutyric acid and D-glucose and by histological examination at the end of experimentation. All chemicals used in this study were of analytical quality and were obtained from commercial sources. Each group of $\mathrm{pH}$ data presented are the result of at least five separate experiments and is expressed as means \pm SEM. $p$ values were calculated by the Student's $t$ test.

\section{RESULTS}

Existence of the ISAM in suckling and weanling rat intestine. The existence of the ISAM in different areas of the intestine of suckling and weanling rats was examined. In all areas tested the intestinal surface $\mathrm{pH}$ was significantly $(p<0.01)$ lower than incubation buffer $\mathrm{pH}$ of $7.39 \pm 0.10$ (Table 1). These observations indicate the existence of the ISAM in suckling and weanling rat intestine. In suckling rats, ISAM $\mathrm{pH}$ was significantly $(p<$ 0.01 ) lower in the proximal jejunum than in the ileum. This observation is similar to that previously reported in our laboratory in adult rats (4). In the colon, however, the ISAM pH was significantly $(p<0.01)$ lower than that reported previously in the proximal and distal colon of adult rats (Table 1). Similar distribution of the ISAM to that noticed in the suckling rats was observed in the intestine of weanling rats with the exception that the ISAM pH of the proximal and distal colon showed a significant $(p<0.01)$ increase toward the adult values (Table 1$)$.

Relationship between buffer pH and ISAM pH in the weanling rat. In this study we examined the effect of varying incubation buffer $\mathrm{pH}$ on jejunal ISAM $\mathrm{pH}$ of weanling rats. The results (Table 2) showed that ISAM pH is not in equilibrium with buffer $\mathrm{pH}$, but rather the ISAM maintains its $\mathrm{pH}$ value in the range of 5.19 to 5.66 over a wide range of buffer $\mathrm{pH}$ (4 to 9 ).

Effect of $N$-acetyl cysteine and stirring on the ISAM of the weanling rat. In this study we examined the effect of the muco- lytic agent NAC (5\% wt/v) on jejunal ISAM pH of weanling rats. NAC caused significant $(p<0.01)$ inhibition in ISAM $\mathrm{pH}$ as compared to controls [ISAM pH of $6.41 \pm 0.1(6)$ and $5.65 \pm$ 0.09 (6) for NAC-treated and untreated (control) tissue, respectively]. This finding indicates that surface mucus plays a role in the maintenance of the ISAM. In another study we examined the effect of vigorous stirring on jejunal ISAM $\mathrm{pH}$ of weanling rats. In this experiment the intestine was everted on a glass rod and then secured on the rod by ligation. The everted intestine on the rod was then spun in Krebs-Ringer phosphate buffer at $1500 \mathrm{rpm}$ for $2 \mathrm{~min}$. At the end of the spinning period, the intestinal tissue was removed and immediately used for ISAM $\mathrm{pH}$ measurements. Stirring caused significant $(p<0.01)$ inhibition in ISAM pH as compared to control [ISAM pH of $6.22 \pm$ 0.06 (7) and $5.65 \pm 0.09$ (6) for stirred and unstirred (control) tissue, respectively]. Stirring in the presence of NAC did not cause a significant increase in the degree of inhibition in ISAM $\mathrm{pH}$ above that observed in the presence of NAC alone [ISAM of $6.48 \pm 0.05(5)$ and $6.41 \pm 0.1(6)$, respectively].

Effect of $\mathrm{Na}^{+}$, glucose, and metabolic inhibitors on the ISAM of the weanling rat. The effect of $\mathrm{Na}^{+}$on jejunal ISAM $\mathrm{pH}$ of weanling rats was examined. ISAM $\mathrm{pH}$ was measured from jejunal tissues incubated under the following conditions: 1) control (tissue incubated immediately after excision in normal Krebs-Ringer phosphate buffer); 2) following incubation for 20 min in a $\mathrm{Na}^{+}$free Krebs-Ringer phosphate buffer (choline replaced $\mathrm{Na}^{+}$for osmolarity), and 3) after incubation for $20 \mathrm{~min}$ in a $\mathrm{Na}^{+}$free medium followed by a 10 -min incubation in a $\mathrm{Na}^{+}$ containing medium. ISAM pH of $5.95 \pm 0.06(6), 6.65 \pm 0.07$ (6), and $6.38 \pm 0.04(6)$ were recorded under these conditions, respectively. As can be seen, incubation in a $\mathrm{Na}^{+}$-free medium caused significant $(p<0.01)$ inhibition in ISAM $\mathrm{pH}$, while reincubation in a $\mathrm{Na}^{+}$-containing medium restored considerable acidity to the jejunal surface.

The effect of glucose and galactose (a hexose which is metabolized only to a small degree by the intestine) (15) on jejunal ISAM $\mathrm{pH}$ of weanling rats was examined. Glucose $(10 \mathrm{mM})$ removal from the incubation medium caused significant $(p<$ 0.01 ) inhibition in the ISAM pH [ISAM pH of $5.8 \pm 0.08$ (6) and $6.90 \pm 0.01(6)$ was observed in the presence and absence of the glucose, respectively]. In the presence of galactose $(10 \mathrm{mM})$ (no glucose added) ISAM pH was similar to that reported in the absence of any sugar [ISAM pH of $6.84 \pm 0.065$ (4) and $6.90 \pm$ $0.16(6)$ was recorded in the presence and absence of galactose respectively].

In another study, we examined the effect of the metabolic inhibitors IA ( $1 \mathrm{mM})$ and DNP $(1 \mathrm{mM})$ on jejunal ISAM $\mathrm{pH}$ of weanling rats. ISAM pH of $5.80 \pm 0.08(16), 6.89 \pm 0.03$ (12), and $6.39 \pm 0.03(12)$ were recorded for control, IA- and DNPtreated tissues, respectively. The inhibition in ISAM $\mathrm{pH}$ was significant in the presence of both inhibitors $(p<0.01)$.

\section{DISCUSSION}

The present study examined the existence and the general characteristics of the ISAM during development. Our results clearly demonstrate the existence of the ISAM in the developing

Table 1. Existence of ISAM in different areas of the intestine in suckling, weanling, and adult rats*

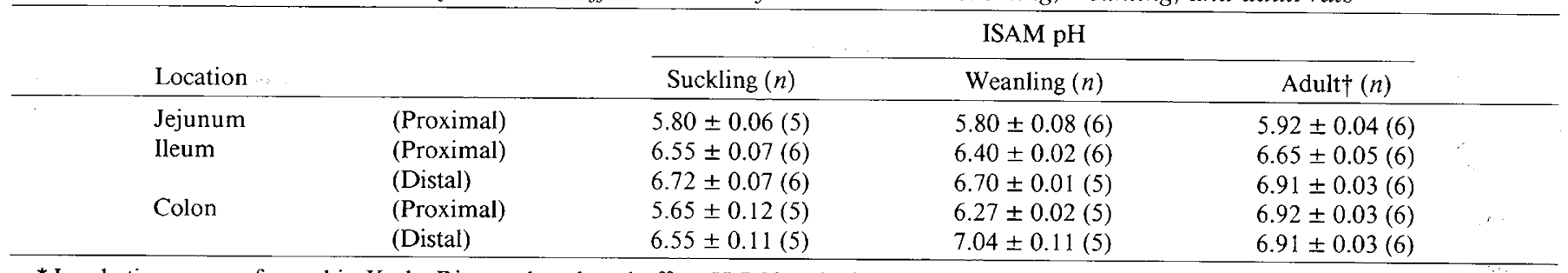

* Incubation was performed in Krebs-Ringer phosphate buffer pH 7.39 \pm 0.10 . Results are means \pm SEM.

† From Reference 4. 
Table 2. Relationship between buffer $p H$ and jejunal ISAM pH of weanling rats*

\begin{tabular}{cc}
\hline Buffer pH $(n)$ & ISAM pH $(n)$ \\
\hline $4.18 \pm 0.02(5)$ & $5.19 \pm 0.06(5)$ \\
$5.95 \pm 0.01(5)$ & $5.34 \pm 0.05(5)$ \\
$6.96 \pm 0.02(5)$ & $5.66 \pm 0.11(5)$ \\
$7.85 \pm 0.02(5)$ & $5.66 \pm 0.08(5)$ \\
$8.95 \pm 0.13(5)$ & $5.65 \pm 0.07(5)$ \\
\hline
\end{tabular}

* Incubation were performed in Krebs-Ringer phosphate buffer. Results are means \pm SEM.

intestine of suckling and weanling rats. The ISAM $\mathrm{pH}$ in the different areas of the small intestine of suckling and weanling rats were similar to those reported previously in our laboratory in the small intestine of adult rats (4). However, differences were observed in the colon. In suckling rats, ISAM pH of both the proximal and the distal colon were significantly $(p<0.01)$ lower than that of adult rats. In weanling rats, the ISAM $\mathrm{pH}$ of the proximal and distal colon showed a considerable increase toward the adult values. The significance of having such an acidic surface in the colon during development, especially in suckling rats, is not clear.

We have previously shown that the ISAM is not an artifact caused by the contact of the $\mathrm{pH}$-microelectrode with the tissue surface and is not a characteristic of an inviable in vitro tissue preparation (4). This was demonstrated by showing: 1) that the ISAM does not exist at the serosal side of the intestinal tissue, but rather serosal surface $\mathrm{pH}$ closely follows incubation buffer $\mathrm{pH}, 2$ ) that the ISAM responds to a variety of conditions such as $\mathrm{Na}^{+}$and glucose removal, metabolic inhibitors and varies in different areas of the intestine, 3) that the intestinal tissue is viable under the conditions of experimentation as assessed by different criteria, and 4) that the ISAM exists in vivo.

It has been suggested by Hogben et al. (1) and Blair and Matty (16) that for the ISAM to exist, it should not be in equilibrium with the bulk phase (incubation medium). The results of our study on the relationship between buffer $\mathrm{pH}$ and ISAM $\mathrm{pH}$ clearly confirm this suggestion by demonstrating that the ISAM $\mathrm{pH}$ resists changes in the incubation buffer $\mathrm{pH}$. What keeps the ISAM from being in equilibrium with bulk phase $\mathrm{pH}$ appears to be the mucus layer at the luminal surface of the intestine. This suggestion is based on the observations that the mucolytic agent NAC and stirring of the incubation medium caused significant inhibition in ISAM pH, observations that are similar to these reported by others (5). Surface mucus helps maintain the ISAM most probably by slowing down the diffusion of $\mathrm{H}^{+}$into (or from) the bulk phase. Indeed, the rate of diffusion of $\mathrm{H}^{+}$in mucus has been shown to be much slower than that in an aqueous phase (17).

$\mathrm{Na}^{+}$appears to be important for the formation and existence of the ISAM of weanling rats. Its removal from the incubation medium caused significant $(p<0.01)$ inhibition in ISAM $\mathrm{pH}$. This inhibition was decreased by readding $\mathrm{Na}^{+}$to the incubation medium. The mechanism by which $\mathrm{Na}^{+}$affects the ISAM is not clear, however, it could be mediated through inhibition in the activity of the $\mathrm{Na}^{+}: \mathrm{H}^{+}$exchange mechanism. This mechanism is thought to be responsible for providing the $\mathrm{H}^{+}$of the ISAM (4, 18 ). The existence of this mechanism in the brush border mem- brane of the intestinal epithelial cells has been well established in recent years $(18-20)$. The observations that glucose but not galactose is essential for the ISAM and that addition of metabolic inhibitors leads to severe inhibition in ISAM acidity indicates that metabolizable substrate(s) and normal intracellular metabolism are essential requirements for the formation and existence of the ISAM.

Recent studies have provided strong evidence for the involvement of the ISAM in the absorption process of certain nutrients $(6-11)$. The demonstration of the existence of the ISAM during development indicates that the developing intestine possesses the necessary means to absorb these important nutrients. In summary, the present study demonstrates the existence of the ISAM in the developing intestine of suckling and weanling rats and shows that the ISAM is not in equilibrium with the bulk phase $\mathrm{pH}$, most probably because of the existence of the surface mucus. Furthermore, the ISAM of the weanling rat requires $\mathrm{Na}^{+}$, glucose, and intracellular metabolism for its formation and normal existence.

\section{REFERENCES}

1. Hogben CMA. Tocco DT, Brodie BB, Schanker LA 1959 On the mechanism of intestinal absorption of drugs. J Pharmacol Exp Ther 125:275-282

2. Lucas ML. Schneider W, Haberich FJ, Blair JA 1975 Direct measurements by $\mathrm{pH}$ microelectrode of the $\mathrm{pH}$ microclimate in rat proximal jejunum. Proc $\mathrm{R}$ Soc Lond 192:39-48

3. Lucas ML, Cooper BT, Lei FH, Johnson IT. Holmes GKT, Blair JA, Cooke WT 1978 Acid microclimate in celiac and Crohn's disease: a model for folate malabsorption. Gut 19:735-742

4. Said HM, Blair JA. Lucas ML. Hilburn ME 1986 Intestinal surface acid microclimate in vitro and in vivo in the rat. J Lab Clin Med 107:420-424

5. Shiau YP, Fernandez M. Jackson M. McDouagle S 1985 Mechanisms maintaining a low pH microclimate in the intestine. Am J Physiol 248:G608G611

6. Said HM, Hollander D. Katz D 1984 Absorption of 5-methyltetrahydrofolate in rat jejunum with intact blood and lymphatic vesicles. Biochim Biophys Acta 775:402-408

7. Said HM, Ghishan FK, Murrell JE 1985 Ontogenesis of the intestinal transport of 5-methyltetrahydrofolate in the rat. Am J Physiol 249:G567-G571

8. Said HM, Ghishan FK. Redha R 1987 Folate transport by human intestinal brush border membrane vesicles. Am J Physiol 252:G229-G236

9. Ganapathy V, Leibach FH 1983 Role of $\mathrm{pH}$ gradient and membrane potential in dipeptide transport in intestinal and renal brush border membrane vesicles from the rabbit. J Biol Chem 258:14189-14192

10. Ganapathy V, Leibach FH 1983 Is intestinal peptide transport energized by a proton gradient? Am J Physiol 249:G153-G160

11. Shiau YF, McMonagle S 1984 Effect of microclimate $\mathrm{pH}$ on intestinal fatty acid uptake. Gastroenterology 86:1248(abstr)

12. Koldovsky O 1969 Development of the Functions of the Small Intestine in Mammals and Man. S Karger, Basel

13. Henning SJ 1987 Functional development of the gastrointestinal tract. In: Johnson LR (ed) Physiology of the Gastrointestinal Tract. Raven Press. New York, pp 285-300

14. Said HM, Greene HL. Moore GC, Ghishan FK 1987 Developmental maturation of D-glucose active transport system in rat intestine. Digestion 36:195200

15. Crane RR 1960 Studies on the mechanism of the intestinal absorption of sugars. III. Mutual inhibition in vitro between some actively-transported sugars. Biochim Biophys Acta 45:477-482

16. Blair JA. Matty AJ 1974 Acid microclimate in intestinal absorption. Clin Gastroenterol 3:183-197

17. Williams SE, Turnberg LA 1980 Retardation of acid diffusion by pig gastric mucus: a potential role in mucosal protection. Gastroenterology 79:299-304

18. Knickelbein R. Aronson PS, Atherton W, Dobbins JW 1983 Sodium and chloride transport across rabbit ileal brush border. I. Evidence for $\mathrm{Na}^{+}: \mathrm{H}^{+}$ exchange. Am J Physiol 245:G504-G510

19. Binder HJ, Stange G, Murer H, Steiger B, Hauri HP 1986 Sodium-proton exchange in colon brush-border membranes. Am J Physiol 251:G382-G390

20. Foster ES, Dudeja PU. Brasitus TA $1986 \mathrm{Na}^{+}: \mathrm{H}^{+}$exchange in rat colonic brush-border membrane vesicles. Am J Physiol 250:G781-G787 